\title{
Investigating the Factors Affecting the Intention to Use E-Learning from the Viewpoint of Higher Education Students
}

\author{
Fatemeh Makkizadeh ${ }^{1,{ }^{*}}$ and Alireza Afshani ${ }^{1}$ \\ ${ }^{1}$ Faculty of Social Sciences, Yazd University, Yazd, Iran \\ "Corresponding author: Faculty of Social Sciences, Yazd University, Daneshgah Blv., Safaeyeh, Yazd, Iran. Tel: +98-913351606, Email: makkizadeh@yazd.ac.ir
}

Received 2018 October 27; Revised 2019 January 21; Accepted 2019 January 22.

\begin{abstract}
Background: E-learning has been considered one of the outstanding applications of information and communication technologies during the past years.

Objectives: The purpose of this study is to investigate the factors affecting the intention of academic individuals to use e-learning with an emphasis on the flow theory.

Methods: This is a descriptive and applied piece of research. The study population included 112 e-learning students in the Virtual Faculty of the Isfahan University, Iran. A conceptual model was presented for the research. Liao's questionnaire was used for data collection. The questionnaire contained 25 items about several factors, including challenge (4 indices), skill ( 4 indices), interaction (3 indices), intermediate variable ( 4 indices), three dependent variables of exploratory use ( 4 indices), intention to use (3 indices), and time distortion (2 indices). Each item was answered on the basis of a 5-point Likert scale, from completely disagree (with score 1) to completely agree (with score 5). Cronbach's alpha value of 0.87 confirmed the reliability of the questionnaire. The descriptive data were analyzed and Pearson test and covariance analysis were conducted by the SPSS software programs version 23 and AMOS version 24.

Results: The findings revealed that skill, challenge, and interactivity have a positive relationship with flow experience which, in turn, is positively related to the intention to use, exploratory use, and time distortion.

Conclusions: The finding of this study is the serious and effective behavior of the users, which can be considered a variable of gaining flow experience in e-learning. It is an important aspect by which the users decide to reuse the system in an exploratory manner with no sense of track of time.
\end{abstract}

Keywords: E-Learning, Acceptance, Flow Theory, Virtual Learner

\section{Background}

Electronic learning is defined as the application of electronic communication technology in education. Following great advances in information and communication technology, electronic learning is regarded as a new paradigm in modern educational methods. E-learning has provided new opportunities for learning in a modern society, leading to a lot of changes in learning. These changes have created a great demand for e-learning in educational institutions as well as businesses (1).

In e-learning, communication media and technologies are used to provide materials and well-designed contents for students. With regard to the rapid development in computer technology, such a learning system is assumed to have evolved from low interactions in written communications to high interactions on the Internet (2). Research has shown that the flow theory is a useful construct by which the user can understand the concepts of computermediated technologies (3-6).

The flow theory was first presented by Csikszentmihalyi (7) as "the state in which people are so intensely involved in an activity that nothing else seems to matter". A flow structure seeks to integrate motivation, personality, and subjective experience. Figure 1 indicates two of the most crucial aspects of the flow theory, namely challenge and skill. According to the following model, "flow channel" is a characteristic of the theory. It is defined as the state of mind that keeps a person focused on an activity. What is expected is that flow experiences occur under an optimal combination of challenge and skill. When the levels of skill and challenge are not compatible, anxiety occurs (i.e. a high task challenge but a low skill level) and boredom (i.e. a high level of skill but a low task challenge) (8).

Some researchers have studied the flow theory in technology and computer-based fields. For example, surveys 


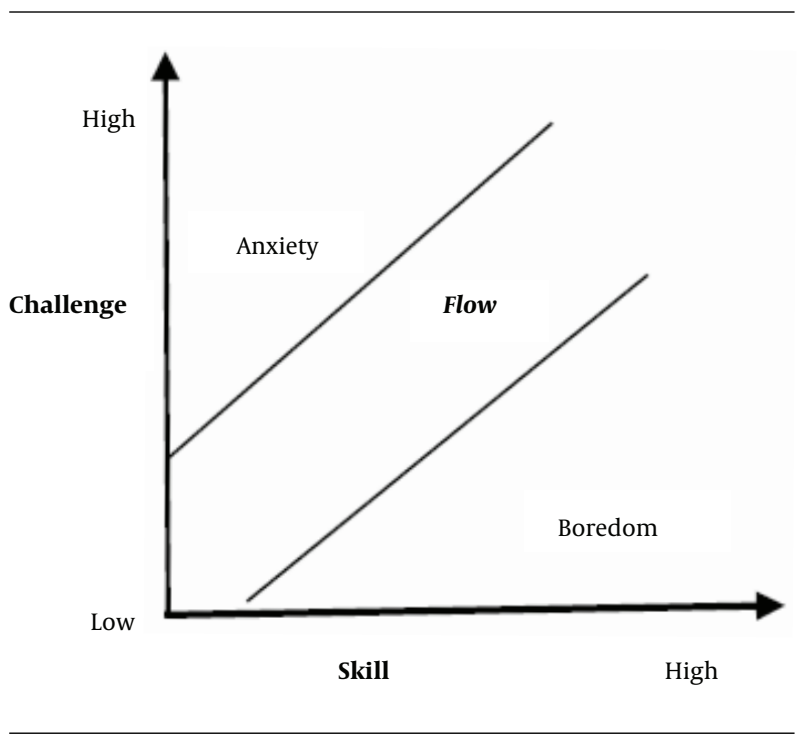

Figure 1. Three channel flow model (8)

have been conducted on computer-mediated communication (CMC) technology by Webster et al. (9); the user navigation behavior in the Web by Novak et al. (10); the effect of augmented reality (AR) learning on the learner's level by Ibáñez et al. (11); learning performance and potential behavior clusters in elementary students by Hsieh et al. (12); and the use of computers and education system to increase students' learning and to generate students' satisfaction by Oliveira dos Santos et al. (13).

The complex essence of human behaviors can influence the application of e-learning systems. The study of factors affecting the application of e-learning by users is one of the scientific approaches by which an individual can optimize the utilization of such education services (14).

Considering the above-mentioned points, this research, which is based on optimal experience, seeks to find out what factors affect e-learning acceptance. In other words, the purpose of the current study is to investigate the factors affecting the intention of academic individuals to use e-learning with an emphasis on the flow theory. In order to respond to this question, the flow theory is implemented in e-learning environments and a model is proposed to clarify the flow status (Figure 2).

The conceptual model of this research is aimed at recognizing the intention to use an e-learning system, emphasizing flow experience based on previous experiences (Figure 2). We define the corresponding variables and present reasons for each of those variables. As it can be seen in the figure, the variables of the model, such as skill, challenge, and interaction, are categorized as flow antecedents. Flow is defined as a holistic sense that people have when they engage in a task. A flow experience has two key character-

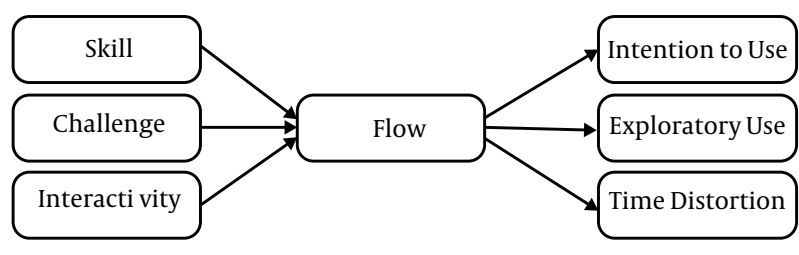

Figure 2. The conceptual model applied in this research

istics including the total concentration on an activity and the enjoyment of being engaged in that activity (7). Here, concentration means the degree of a person's attention on an activity, and enjoyment is how a person finds the use of the system without focusing on the consequences (15).

The probability of using a system by a person is called intention to use. The intention to use is defined as a duration in which someone is engaged with technology, uses it, and repeats the use. Many studies have confirmed the positive relationship of flow to the intention of using, for example, distance education (16) or social networks (17). In this study, the intention to use is defined as the probability of using an e-learning system.

Exploratory use refers to the searching of a system for its new functions. Also, time distortion points to a situation in which people do not feel the lapse of time when they are using a system (7). An overview of the literature shows that, after users sense the flow, they have common experiences. Common experiences include exploratory behavior, intention to use, and time distortion (16). As a result, in the present research, intention to use, exploratory use, and time distortion were regarded as the exogenous variables of the model.

Skills are defined as users' confidence to overcome those barriers, which hinder them from using an elearning system. The level of an individual's skills is an important antecedent of flow $(7,13,18,19)$.

Challenge is defined as the level of difficulty that a user perceives when dealing with an e-learning system. Like skill, the challenge is one of the most important antecedents of flow $(7,10,13,18)$. When handling an e-learning system, a user should perform so well as to achieve his or her goals of gaining access to the target information.

Interactivity is an important factor in humancomputer interactions (16). Many researchers believe that optimal experience in an interactive environment can enhance communication and exploratory behavior (20-22). Thus in the present study, interactivity is considered one of the antecedents of flow.

\subsection{The Hypotheses of the Study}

1- Flow experience is positively related to intention to use. 
2- Flow experience is positively related to exploratory use.

3- Flow experience is positively related to perceived time distortion.

4-Skill is positively related to flow experience.

5 - Challenge is positively related to flow experience.

6- Interactivity is positively related to flow experience.

\section{Methods}

This research is a survey conducted with a statistical population that initially included all the M.S. students who had started their courses in 2017. Indeed, the sample was selected of the students who had passed at least three semesters in the Virtual Faculty of the University of Isfahan. They were specializing in three disciplines, including Master of Business Administration (MBA), Executive MBA, and Knowledge of Information and Science (KIS). For data collection, an electronic questionnaire was delivered to each of them either by e-mail or in person. In this study, the sample size was calculated through the Morgan Table. The participants were selected by random sampling. Finally, of all the questionnaires delivered 112 were received and accepted.

The data collection tool was the questionnaire devised by Liao (16). It was tailored to the conceptual model of the research. The questionnaire contained 25 items regarding several factors, including challenge ( 4 indices), skill ( 4 indices), interaction (3 indices), intermediate variables ( 4 indices) as well as three dependent variables of exploratory use ( 4 indices), intention to use ( 3 indices) and time distortion (2 indices). Each item was answered on the basis of the 5-point Likert scale, from completely disagree (score 1) to completely agree (score 5). In order to test the conceptual model of this research, we used covariance-based structural equation modeling. For this purpose, the SPSS software was used to analyze the data extracted from the questionnaires and AMOS. The reliability of the questionnaire was determined by Cronbach's alpha coefficient and the content validity was evaluated by assessing the validity of the indicators used in the questionnaire. This was done separately from the review of the research background. In addition, confirmatory factor analysis and assurance of the significance of the factor loads of each investigated component indicated the construct validity of the questionnaire. Cronbach's alpha value of 0.87 signified the tool reliability.

In order to analyze the data, SPSS version 23 and AMOS version 24 were used. The data received from the questionnaires were entered in a computer after they were coded by the Likert method. First, a descriptive analysis was performed on the demographic characteristics of the subjects. In this case, means, standard deviations, percentages, and frequencies were used. Participation in this study was optional. The participants were also assured that all the collected data would be kept confidential.

Out of 112 respondents, 33 and 79 were men and women, respectively. They ranged from 26 to 31 years of age. As they reported, 36.6 percent of them had spent 1 to 5 hours per week using an e-learning system, while 63.4 percent had spent more than 5 hours per week doing that.

\section{Results}

The structural equations modeling (SEM) was done to test the research hypotheses. The data were analyzed through the Amos-24 software. Table 1 presents the results of the descriptive analysis of the model variables.

\begin{tabular}{lcc}
\hline Table 1. Descriptive Analysis of the Research Variables $(\mathrm{N}=112)$ & \\
\hline Variable & Mean \pm SD & Variance \\
\hline Skill & $10.06 \pm 2.187$ & 4.784 \\
Challenge & $13.14 \pm 2.813$ & 7.911 \\
\hline Interaction & $9.66 \pm 2.023$ & 4.094 \\
Exploratory use & $10.48 \pm 1.908$ & 3.642 \\
\hline Intention to use & $11.31 \pm 2.274$ & 5.171 \\
\hline Time distortion & $7.41 \pm 1.957$ & 3.829 \\
\hline Flow & $20.80 \pm 4.042$ & 16.335 \\
\hline
\end{tabular}

The questionnaire validity was measured through a confirmatory factor analysis by principal component extraction and varimax rotation. The resulting KMO figure was 0.783 , the Bartlett figure stood at 2373.847, and the degree of freedom was significant at $742(\mathrm{P}<0.001)$. Cronbach's alpha for the reliability of the questionnaire was 0.87 .

\subsection{Structural Equation Modeling}

A statistical analysis of the model assumptions was performed to quantitatively define the correlation levels among the variables based on the data obtained. Using the correlation figures, the path coefficients, which were regression standard coefficients (beta), were determined. The highest correlation was observed between flow and time distortion (0.752). The range of the other correlations indicates the strength of the relationships among the dependent and independent variables (Table 2).

In this study, the model's overall goodness of fit to the data was desirable. The comparative fit index (CFI), the incremental fit index (IFI), the Tucker-Lewis index (TLI), and the goodness-of-fit index (GFI) were found to be 0.917 , $0.919,0.903$, and 0.901 , respectively. A value above 0.90 


\begin{tabular}{|c|c|c|c|c|c|c|}
\hline & Skill & Challenge & Interaction & Exploratory Use & Intention to Use & Time Distortion \\
\hline Challenge & $0.222^{\mathrm{a}}$ & & & & & \\
\hline Interaction & $0.416^{\mathrm{b}}$ & $0.146^{c}$ & & & & \\
\hline Exploratory Use & $0.454^{\mathrm{b}}$ & $0.437^{\mathrm{b}}$ & $0.335^{\mathrm{b}}$ & & & \\
\hline Intention to Use & $0.276^{\mathrm{b}}$ & $0.377^{\mathrm{b}}$ & $0.230^{\mathrm{a}}$ & $0.420^{\mathrm{b}}$ & & \\
\hline Time Distortion & $0.199^{\mathrm{a}}$ & $0.294^{\mathrm{b}}$ & 0.074 & $0.345^{\mathrm{b}}$ & $0.402^{\mathrm{b}}$ & \\
\hline Flow & $0.403^{\mathrm{b}}$ & $0.412^{\mathrm{b}}$ & $0.345^{\mathrm{b}}$ & $0.528^{\mathrm{b}}$ & $0.635^{\mathrm{b}}$ & $0.752^{\mathrm{b}}$ \\
\hline
\end{tabular}

was considered to be an indicator of good fit. The normed chi-square (CMIN) was also lower than the acceptable value (i.e. lower than 3). The root mean-square error of approximation (RMSEA) had an acceptable level on the goodness of fit of the model. Table 3 provides the fitness indexes.

\begin{tabular}{lcc}
\hline Table 3. Goodness of Fit Indexes & & \\
\hline Fitness Indexes & Amount & Acceptance Range \\
\hline Chi-square & 336.005 & - \\
\hline DF & 218 & - \\
\hline Chi-square/DF ratio & 1.541 & $<3$ \\
\hline GFI & 0.901 & $>0.90$, acceptable \\
\hline TLI & 0.903 & $>0.90$, acceptable \\
\hline RMSEA & 0.060 & $<0.08$, acceptable \\
\hline CFI & 0.917 & $>0.90$, acceptable \\
\hline PCFI & 0.790 & $>0.50$, acceptable \\
\hline IFI & 0.919 & $>0.90$, acceptable \\
\hline $\begin{array}{l}\text { Abbreviations: CFI, comparative fit index; DF, degree of freedom; GFI, goodness- } \\
\text { of-fit index; IFI, incremental fit index; RMSEA, root mean-square error of approx- } \\
\text { imation; TLI, Tucker-Lewis index. }\end{array}$ &
\end{tabular}

The results of the structural equation analysis are provided in Figure 3 and Table 4. As in Figure 3, the research model was mapped in order to show how the corresponding concepts or factors are related together.

The research data supported hypotheses 1,2 , and 3 . In other words, flow experience has a positive and significant effect on intention to use $(\beta=0.60 ; t=5.640 ; \mathrm{P}<0.001)$, exploratory to use $(\beta=0.73 ; t=5.522 ; \mathrm{P}<0.001)$, and time distortion $(\beta=0.54 ; t=4.662 ; \mathrm{P}<0.001)$.

Also, as shown in Table 4, the results supported hypothesis 4 ; user skill has a significant effect on flow experience $(\beta=0.20 ; t=1.992 ; \mathrm{P}<0.05)$. The results supported hypothesis 5 as well; user challenge has a significant effect on flow experience ( $\beta=0.46 ; t=4.297 ; \mathrm{P}<0.01$ ); Hypothesis 6 is supported too; user interactivity has a significant effect on flow experience $(\beta=0.37 ; t=3.030 ; \mathrm{P}<0.01)$. The standard path coefficients of the proposed model, demonstrated in Table 4 are all significant.

Among the mentioned cases, the flow construct has the greatest impact on exploratory use. According to the results, the flow hypothesis theory can be used in an environment where a user is in interaction with an e-learning system.

\section{Discussion}

It was demonstrated in this research that the flow theory can be applied to e-learning environments. The findings revealed that skill, challenge, and interactivity construct have a positive relationship with flow experience. This is in agreement with the results reached by Ghani and Desphande (23), Hamari et al. (19), Liao (16), and Hsieh et al. (12). The important factors in the flow theory are skill and challenge. Obviously, individuals with higher levels of skill and self-efficiency can have better specifications when dealing with computers and experience a state of flow more easily $(19,24)$. The more comfortably the users can work with a system and the more engaged they are with that system while using it; the better they experience the flow.

The findings of this research reveal that interactivity construct affects the flow experience. As individuals develop through interactivity with other individuals, they also undergo cognitive and behavioral evolutions through interacting with machines and computers $(12,19)$. A rich interactive relationship between the user and the system gives him or her an optimal experience and encourages future reuses. A number of prior researchers have stated that achieving the flow experience through interactivity with other users facilitates learning $(16,25)$.

After the individuals feel the flow, they gain common experiences. Since the flow experience comes through users' cognition, emotion, interactivity, and skill of mutual interactivity with the system, their satisfaction is almost ensured; consequently, such a situation facilitates 


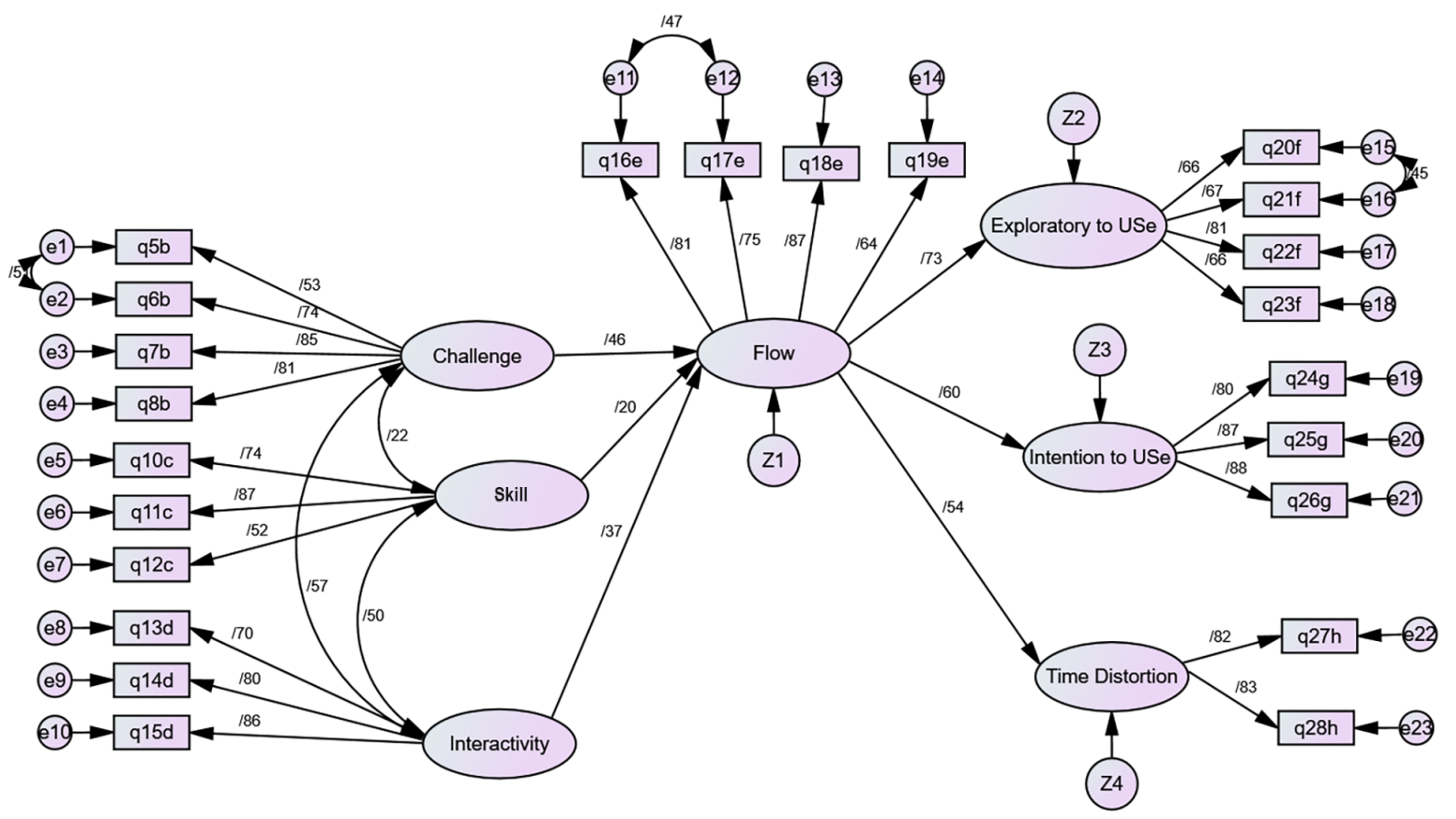

\begin{tabular}{|c|c|c|c|}
\hline Path & Non-Standard Coefficient & Standard Coefficient & Consequent Hypothesis \\
\hline Skill to flow & 0.27 & 0.20 & Accepted \\
\hline Challenge to flow & 0.46 & 0.46 & Accepted \\
\hline Interaction to flow & 0.32 & 0.37 & Accepted \\
\hline Flow to intention to use & 0.64 & 0.60 & Accepted \\
\hline Flow to exploratory to use & 0.45 & 0.73 & Accepted \\
\hline Flow to time distortion & 0.49 & 0.54 & Accepted \\
\hline
\end{tabular}

searching, navigation, and reusing, as the required behaviors in an e-learning environment. Many researchers have shown that flow increases communication (9), exploratory behavior $(9,23,25)$, learning $(13,16)$, and computer use in this environment $(9,19,23)$.

The findings in this research are similar to those in prior research. After the students experience the flow, many positive attitudes develop, including exploratory behavior, and intention to use. Considering the prior research, a user neglects the concept of time when intending to do an activity and discovers new mechanisms of activity. Oliveira dos Santos et al. (13) proved that flow has a positive relationship with experience, voluntary use, and real use. Liao (16) demonstrated that flow has a significant impact on exploratory use.

The findings of the current research as well as the comments made above are all in agreement with those in previous studies that have ever dealt with the abovementioned concepts of significance in computer environments. In addition, part of the findings here regards the serious and effective behavior of users as an important novel aspect. This aspect is, indeed, a variable of flow experience in e-learning, by which the users decide to reuse the system through exploratory use with no sense of track of time. Eventually, the positive attitude of the users for reusing e-learning systems leads to boost "the flow theory" through gaining experience. The results of this research also expand new horizons for further research on users' 
behaviors. Some factors other than those examined in the present study, such as focus of attention and control, may affect the acceptance of e-learning. Hence, further study is needed. The relationships found among the variables in this research provide good topics to study in other fields. Any similar research on those subjects will reinforce the theoretical framework presented in this study.

\section{Acknowledgments}

We would also like to show our gratitude to the Yazd University officials for providing the opportunity to research, as well as the college officials of the Isfahan University. The authors also wish to thank the virtual students, from Isfahan universities who participated in this study.

\section{Footnotes}

Authors' Contribution: The authors developed the original idea and the protocol, abstracted and analyzed data, wrote the manuscript, and is the guarantor. The authors contributed to the development of the protocol, technical support, and Statistical analysis. The authors contributed to the design and analysis of the study data and drafted the manuscript.

Conflict of Interests: The authors declare that there is no conflict of interest regarding this paper.

Ethical Approval: It is not declared by the authors.

Funding/Support: The authors declare that they received no fund for this study.

Informed Consent: Participation in this study was optional. After obtaining approval from the college officials, the questionaries' were distributed among the students and also assured them that all information collected will remain confidential.

\section{References}

1. Katz YJ. The comparative suitability of three ICT distance learning methodologies for college level instruction. Educ Media Int. 2000;37(1):25-30. doi:10.1080/095239800361482.

2. Moore MG, Kearsley G. Distance education: A systems view. Belmont, CA: Wadsworth; 1996.

3. Admiraal W, Huizenga J, Akkerman S, Dam G. The concept of flow in collaborative game-based learning. Comput Hum Behav. 2011;27(3):1185-94. doi: 10.1016/j.chb.2010.12.013.

4. Santos WO, Bittencourt II, Isotani S, Silveira FI, Marques LB. Challenges of flow theory applied to computers in education. IVWorkshop of Challenges of Computer in Education. Recife-PE, Brazil.[GS Search]. 2015.

5. Challco GC, Moreira D, Mizoguchi R, Isotani S. Towards an ontology for gamifying collaborative learning scenarios. International Conference on Intelligent Tutoring Systems. Springer; 2014. p. 404-9.
6. dos Santos WO, Gomes T, Silva C. Towards to flow state identification in educational games: An empirical study. Brazilian Symposium on Computers in Education (Simpósio Brasileiro de Informática na EducaçãoSBIE). 2017. 927 p.

7. Csikszentmihalyi M. Flow: The psychology of optimal experience. New York: Harpers Perennial; 1990.

8. Rha I, Williams MD, Heo G. Optimal flow experience in web-based instruction. Asia Pac Educ Rev. 2005;6(1):50-8. doi: 10.1007/bf03024967.

9. Webster J, Trevino LK, Ryan L. The dimensionality and correlates of flow in human-computer interactions. Comput Human Behav. 1993;9(4):411-26. doi: 10.1016/0747-5632(93)90032-N.

10. Novak TP, Hoffman DL, Yung YF. Modeling the structure of the flow experience among web users. INFORMS Marketing Science and the Internet Mini-Conference. Boston, MA. 1998.

11. Ibáñez MB, Di Serio Á, Villarán D, Kloos CD. Experimenting with electromagnetism using augmented reality: Impact on flow student experience and educational effectiveness. Comput Educ. 2014;71:1-13.

12. Hsieh Y, Hou H, Lin Y. Exploring the role of flow experience, learning performance and potential behavior clusters in elementary students' game-based learning. Interact Learn Envir.2016;24(1):178-93. doi: $10.1080 / 10494820.2016 .834827$.

13. Oliveira dos Santos W, Bittencourt II, Isotani S, Dermeval D, Brandão Marques L, Frango Silveira I. Flow theory to promote learning in educational systems: Is it really relevant? Braz J Comput Educ 2018;26(2):29. doi: 10.5753/rbie.2018.26.02.29.

14. Chan TS, Ahern TC. Targeting motivation: Adapting flow theory to instructional design. J Educ Comput Res. 2016;21(2):151-63. doi: 10.2190/uj04-t5yb-yfxe-obg2.

15. Davis FD, Bagozzi RP, Warshaw PR. Extrinsic and intrinsic motivation to use computers in the workplace1.J Appl Soc Psychol.1992;22(14):111132. doi: 10.1111/j.1559-1816.1992.tb00945.x.

16. Liao LF. A flow theory perspective on learner motivation and behavior in distance education. Distance Educ. 2006;27(1):45-62. doi: 10.1080/01587910600653215.

17. Lin KY, Lu HP. Why people use social networking sites: An empirical study integrating network externalities and motivation theory. Comput Hum Behav. 2011;27(3):1152-61. doi: 10.1016/j.chb.2010.12.009.

18. Liu SH, Liao HL, Pratt JA. Impact of media richness and flow on elearning technology acceptance. Comput Educ. 2009;52(3):599-607. doi: 10.1016/j.compedu.2008.11.002.

19. Hamari J, Shernoff DJ, Rowe E, Coller B, Asbell-Clarke J, Edwards T. Challenging games help students learn: An empirical study on engagement, flow and immersion in game-based learning. Comput Hum Behav. 2016;54:170-9. doi:10.1016/j.chb.2015.07.045.

20. Davis FD, Bagozzi RP, Warshaw PIR. User acceptance of computer technology: A comparison of two theoretical models. Manag Sci. 1989;35(8):982-1003. doi: 10.1287/mnsc.35.8.982.

21. Finneran CM, Zhang P. A person-artefact-task (PAT) model of flow antecedents in computer-mediated environments. Int J Hum-Comput St. 2003;59(4):475-96. doi: 10.1016/s1071-5819(03)00112-5.

22. Liu CC, Chang IC. Measuring the flow experience of players playing online games. PACIS. 2012.104 p.

23. Ghani JA, Deshpande SP. Task characteristics and the experience of optimal flow in human-computer interaction. J Psychol. 1994;128(4):38191. doi: 10.1080/00223980.1994.9712742.

24. Lin KM. e-Learning continuance intention: Moderating effects of user e-learning experience. Comput Educ. 2011;56(2):515-26. doi: 10.1016/j.compedu.2010.09.017.

25. Ghani JA. Flow in human computer interactions: Test of a model. In Carey J, editor. Human factors in information systems: Emerging theoretical bases. Norwood, NJ: Ablex; 1995. p. 291-311. 